\title{
Effect of non-invasive ventilation on respiratory muscle loading and endurance in patients with Duchenne muscular dystrophy
}

\author{
M Toussaint, ${ }^{1}$ P Soudon, ${ }^{1}$ W Kinnear ${ }^{2}$
}

${ }^{1}$ Centre for Home Mechanical Ventilation, Ziekenhuis Inkendaal, Vlezenbeek, Belgium; ${ }^{2}$ Department of Respiratory Medicine, University Hospital, Nottingham, UK

Correspondence to: Dr M Toussaint, ZH Inkendaal, Inkendaalstraat 1, 1602 Vlezenbeek, Belgium; michel. toussaint@inkendaal.be

Received 21 May 2007 Accepted 21 November 2007 Published Online First 5 December 2007

\begin{abstract}
Background: Respiratory muscle weakness in patients with Duchenne muscular dystrophy (DMD) leads to respiratory failure for which non-invasive positive pressure ventilation (NIPPV) is an effective treatment. This is used initially at night (n-NIPPV) but, as the disease progresses, diurnal use (d-NIPPV) is often necessary. The connection between NIPPV and relief of respiratory muscle fatigue remains unclear. A study was undertaken to determine the extent to which n-NIPPV and d-NIPPV unload the respiratory muscles and improve respiratory endurance in patients with DMD.
\end{abstract}

Methods: Fifty patients with DMD were assessed at 20.00 and $08.00 \mathrm{~h}$. More severely affected patients with nocturnal hypoventilation received n-NIPPV; those with daytime dyspnoea also received d-NIPPV via a mouthpiece (14.00-16.00 h). Lung function, modified Borg dyspnoea score, spontaneous breathing pattern, tensiontime index $\left(\Pi_{0.1}=\right.$ occlusion pressure $\left(\mathrm{P}_{0.1}\right) /$ maximum inspiratory pressure $(\mathrm{MIP}) \times$ duty cycle $(\mathrm{Ti} /$ totot)) and respiratory muscle endurance time (Tlim) against a threshold load of 35\% MIP were measured.

Results: More severe respiratory muscle weakness was associated with a higher $T_{0.1}$ and lower Tlim. In contrast to non-dyspnoeic patients, patients with dyspnoea (Borg score $>2.5 / 10$ ) showed an increase in Tlim and decrease in $T_{01}$ after n-NIPPV. At $16.00 \mathrm{~h}$, immediately after $\mathrm{d}$ NIPPV, patients with dyspnoea had lower $\mathrm{T}_{0.1}$ and Borg scores with unchanged Tlim. Compared with the control day without d-NIPPV, $T_{0.1}$, Borg scores and Tlim were all improved at $20.00 \mathrm{~h}$.

Conclusions: In patients with dyspnoea with DMD, the load on respiratory muscles increases and endurance capacity decreases with increasing breathlessness during the day, and this is reversed by n-NIPPV. An additional $2 \mathrm{~h}$ of $d$-NIPPV unloads respiratory muscles and reverses breathlessness more effectively than n-NIPPV alone.

Duchenne muscular dystrophy (DMD) is an Xlinked disorder which affects skeletal muscles including those of respiration. Vital capacity $(\mathrm{VC})^{1}$ and respiratory endurance ${ }^{2}$ start to decline in adolescence, and without non-invasive intermittent positive pressure ventilation (NIPPV) death occurs at an average age of 21.5 years. ${ }^{3}$

In order to minimise the work ${ }^{4}$ and perception ${ }^{5}$ of breathing, patients progressively accelerate their respiratory rate. Despite this strategy, at some stage it is no longer possible to maintain adequate alveolar ventilation and the arterial carbon dioxide pressure $\left(\mathrm{PaCO}_{2}\right)$ rises. Nocturnal hypercapnia typically occurs when the VC falls below $40 \%$ of the predicted value, ${ }^{67}$ and further progresses to diurnal hypercapnia within 12 months in $70 \%$ of cases. ${ }^{8}$ With the use of nocturnal NIPPV (nNIPPV), daytime hypercapnia is delayed by 4 5 years $^{9}$ and survival is prolonged by $5-10$ years. ${ }^{10}$ Diurnal NIPPV (d-NIPPV) delays further deterioration in VC and prolongs survival above 31 years. ${ }^{9}$

In $\mathrm{DMD}$, failure to maintain alveolar ventilation could plausibly be explained by fatigue of the respiratory muscles, although this has never been convincingly demonstrated. Studies of the longterm effects of NIPPV have concluded that improved respiratory drive is the most important factor in restoring alveolar ventilation in patients with neuromuscular disease,$^{11}{ }^{12}$ but reducing respiratory drive seems more likely to be a protective mechanism for fatiguing respiratory muscles than the primary problem in DMD.

We studied non-ambulatory patients with DMD at different stages of respiratory progression up to the ultimate stage in which permanent assisted ventilation is expected. We used two different but complementary techniques-modified non-invasive tension-time index and endurance of a threshold load-to investigate the effects of NIPPV on respiratory muscle loading and endurance capacity in patients with DMD. Our hypothesis was that nocturnal NIPPV initiated at the onset of nocturnal hypercapnia does not unload the respiratory muscles, whereas both nocturnal and part-time daytime NIPPV unload respiratory muscles in patients complaining of increasing dyspnoea during daytime unassisted breathing.

\section{METHODS}

Fifty consecutive patients with DMD of mean (SD) age of $21.6(5.7)$ years, weight $54.3(18.8) \mathrm{kg}$ and arm span $164.3(8.4) \mathrm{cm}$ were studied. They were divided into five groups according to the clinical severity of their respiratory muscle involvement. Patients in group $1(n=10)$ were able to breathe spontaneously all day and night and had normal nocturnal gas exchange. Those in group 2 $(n=9)$ were also able to breathe spontaneously all day and night but had asymptomatic nocturnal hypoventilation as evidenced by a transcutaneous carbon dioxide tension $\left(\mathrm{TcCO}_{2}\right)$ which rose above $45 \mathrm{~mm} \mathrm{Hg}$. Group $3(\mathrm{n}=11)$ and group $4(\mathrm{n}=11)$ had been commenced on n-NIPPV to correct symptomatic nocturnal hypoventilation. In a previous study we found that subjects who were breathless in the evening prior to restarting $\mathrm{n}$ NIPPV were more likely to benefit from d-NIPPV. We therefore subdivided patients using n-NIPPV according to the presence (group 4) or absence 
(group 3) of a modified Borg dyspnoea score on 10 points in the evening of $>2.5$. Patients in group $5(n=9)$ already used NIPPV for symptom relief during the day as well as at night. Symptoms were rated by a score with a total of seven points, ${ }^{913}$ one point for the presence of each of the following symptoms: chronic secretions and cough, perceived dyspnoea, anorexia, moodiness, hand sweating, headache and dysphagia.

In experiment 1 we studied the effect of n-NIPPV on respiratory muscle loading by comparing evening and morning measurements made at 20.00 and 08.00 h. n-NIPPV (groups 3 and 4) was provided by volume ventilators for a mean (SD) of 8.9 (0.9) h using a nasal mask. The ventilators were set initially with a tidal volume (VT) of $12 \mathrm{ml} / \mathrm{kg}$ at a slightly lower respiratory rate $(R R)$ than the spontaneous rate during sleep. ${ }^{14}$ After adjusting the settings to maintain normocapnia with minimal mask leaking, mean (SD) VT and RR were 653 (71) $\mathrm{ml}$ and $19.9(1.7) / \mathrm{min}$, respectively.

In experiment 2 , patients in group 4 (evening dyspnoea) received additional d-NIPPV by mouthpiece between 14.00 and $16.00 \mathrm{~h}$. This duration and timing of d-NIPPV reflected use in clinical practice where a $2 \mathrm{~h}$ period in the middle of the day relieves symptoms with minimal intrusion on daily activities. ${ }^{15}$

Measurements were made at 16.00 and $20.00 \mathrm{~h}$ on days with d-NIPPV and compared with data recorded at 08.00, 14.00 and $20.00 \mathrm{~h}$ on a separate day after n-NIPPV alone. The same ventilator settings were used for d-NIPPV as for n-NIPPV but with a mouthpiece held in place by a rigid plastic retainer placed on the shoulder of the patient. ${ }^{9}$

Respiratory muscle loading was assessed using two different approaches: spontaneous breathing pattern and respiratory muscle endurance. For breathing pattern, subjects were asked to breathe through a mouthpiece for $2 \mathrm{~min}$, from which a $30 \mathrm{~s}$ sequence of regular breathing was selected for further analysis. $\mathrm{RR}$, inspiratory time ( $\mathrm{Ti}$ ), total breath time (Ttot), duty cycle
(Ti/Ttot), VT and minute ventilation (VE) were calculated. While breathing quietly, 10 records of $100 \mathrm{~ms}$ occlusion pressure $\left(\mathrm{P}_{0.1}\right)$ were electronically triggered in random order over a period of $2 \mathrm{~min}$. The mean value from the three best $\mathrm{P}_{0.1}$ records was retained for analysis. ${ }^{16}$ Volumes and timing of spontaneous ventilation were obtained by integration of flow signals

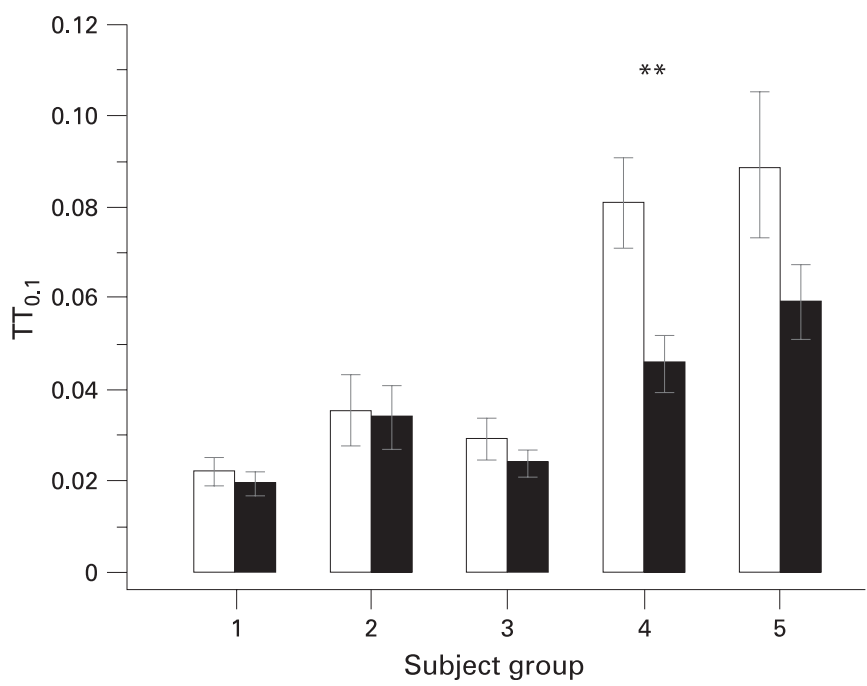

Figure 1 Non-invasive tension-time index $\left(\mathrm{TT}_{0.1}\right)$ in the five groups of patients with Duchenne muscular dystrophy. Columns represent mean values; errors bars represent 1 standard error of the mean (SEM). White columns: evening $\mathrm{TT}_{0.1}$; black columns: morning $\mathrm{TT}_{0.1} ;{ }^{* *} \mathrm{p}<0.01$ (paired $t$ test, evening vs morning). Group 1, no assisted ventilation (NIPPV) and 24/24 h normocapnia; group 2, nocturnal hypercapnia prior to start of NIPPV implementation; group 3, nocturnal NIPPV with no breathlessness; group 4, nocturnal NIPPV with breathlessness; group 5, full-time NIPPV.

Table 1 Demographic data of the five groups of patients with Duchenne muscular dystrophy: morning measurements

\begin{tabular}{|c|c|c|c|c|c|}
\hline & Group 1 & Group 2 & Group 3 & Group 4 & Group 5 \\
\hline Age (years) $)^{* *}$ & $\begin{array}{l}17(2.9) \\
(14.9 \text { to } 19.1)\end{array}$ & $\begin{array}{l}18.6(2.8) \\
(16.4 \text { to } 20.7)\end{array}$ & $\begin{array}{l}21.6(4.6) \\
(18.6 \text { to } 24.7)\end{array}$ & $\begin{array}{l}22.2(3.3) \\
(19.9 \text { to } 24.4)\end{array}$ & $\begin{array}{l}29.1(6.2) \\
(24.5 \text { to } 33.8)\end{array}$ \\
\hline BMI $\left(\mathrm{kg} / \mathrm{m}^{2}\right)$ & $\begin{array}{l}21.7(6.5) \\
(13 \text { to } 28.2)\end{array}$ & $\begin{array}{l}20.7(6.2) \\
(16 \text { to } 25.3)\end{array}$ & $\begin{array}{l}20.9(8.8) \\
(15 \text { to } 26.8)\end{array}$ & $\begin{array}{l}18.3(6.8) \\
(13.7 \text { to } 22.8)\end{array}$ & $\begin{array}{l}18.8(5.4) \\
(14.8 \text { to } 22.8)\end{array}$ \\
\hline $\operatorname{VC}(\%)^{* * *}$ & $\begin{array}{l}44.5(16) \\
(33.1 \text { to } 55.9)\end{array}$ & $\begin{array}{l}23.3(5.4) \\
(19.2 \text { to } 27.5)\end{array}$ & $\begin{array}{l}25.9(8.4) \\
(20.3 \text { to } 31.6)\end{array}$ & $\begin{array}{l}14.8(4.2) \\
(12 \text { to } 17.6)\end{array}$ & $\begin{array}{l}12.1(2.4) \\
(10.2 \text { to } 14)\end{array}$ \\
\hline $\operatorname{MVV}(\mathrm{l} / \mathrm{min})^{* * *}$ & $\begin{array}{l}60.8(18.1) \\
(47.9 \text { to } 73.7)\end{array}$ & $\begin{array}{l}34.7(8.2) \\
(28.4 \text { to } 41)\end{array}$ & $\begin{array}{l}41.4(11.7) \\
(33.5 \text { to } 49.2)\end{array}$ & $\begin{array}{l}26.4(13.6) \\
(17.2 \text { to } 35.4)\end{array}$ & $\begin{array}{l}18.2(4.0) \\
(15.2 \text { to } 21.3)\end{array}$ \\
\hline $\mathrm{VT}(\mathrm{ml})^{* *}$ & $\begin{array}{l}425(188) \\
(291 \text { to } 559)\end{array}$ & $\begin{array}{l}252(88) \\
(184 \text { to } 320)\end{array}$ & $\begin{array}{l}305(74) \\
(256 \text { to } 355)\end{array}$ & $\begin{array}{l}274(84) \\
(218 \text { to } 331)\end{array}$ & $\begin{array}{l}241(44) \\
\text { (208 to 275) }\end{array}$ \\
\hline $\mathrm{RR}$ (breath/min)** & $\begin{array}{l}17.5(5) \\
(13.9 \text { to } 21.1)\end{array}$ & $\begin{array}{l}22.4(6.4) \\
(17.6 \text { to } 27.3)\end{array}$ & $\begin{array}{l}19.3(4.1) \\
(16.6 \text { to } 21.9)\end{array}$ & $\begin{array}{l}19.6(2.5) \\
(17.9 \text { to } 21.2)\end{array}$ & $\begin{array}{l}24.8(4.8) \\
(21.1 \text { to } 28.5)\end{array}$ \\
\hline VE $(I / \min )$ & $\begin{array}{l}6.9(2.2) \\
(5.3 \text { to } 8.5)\end{array}$ & $\begin{array}{l}5.3(1.7) \\
(4 \text { to } 6.6)\end{array}$ & $\begin{array}{l}5.8(1.4) \\
(4.8 \text { to } 6.7)\end{array}$ & $\begin{array}{l}5.4(1.7) \\
(4.2 \text { to } 6.6)\end{array}$ & $\begin{array}{l}5.9(1.1) \\
(5.0 \text { to } 6.8)\end{array}$ \\
\hline $\mathrm{Ti} / \mathrm{Tt}$ tot & $\begin{array}{l}0.46(0.04) \\
(0.44 \text { to } 0.49)\end{array}$ & $\begin{array}{l}0.44(0.08) \\
(0.39 \text { to } 0.5)\end{array}$ & $\begin{array}{l}0.41(0.08) \\
(0.36 \text { to } 0.46)\end{array}$ & $\begin{array}{l}0.44(0.04) \\
(0.41 \text { to } 0.47)\end{array}$ & $\begin{array}{l}0.43(0.05) \\
(0.40 \text { to } 0.47)\end{array}$ \\
\hline $\operatorname{MIP}\left(\mathrm{cm} \mathrm{H}_{2} \mathrm{O}\right)^{* * *}$ & $\begin{array}{l}46.7(14.8) \\
(36.1 \text { to } 57.2)\end{array}$ & $\begin{array}{l}24.1(8.5) \\
(17.6 \text { to } 30.6)\end{array}$ & $\begin{array}{l}26.9(10.1) \\
(20.1 \text { to } 33.7)\end{array}$ & $\begin{array}{l}14(5.6) \\
(10.2 \text { to } 17.7)\end{array}$ & $\begin{array}{l}11.1(3.2) \\
(8.7 \text { to } 13.5)\end{array}$ \\
\hline$P_{0.1}$ & $\begin{array}{l}1.84(0.78) \\
(1.28 \text { to } 2.4)\end{array}$ & $\begin{array}{l}1.61(0.37) \\
(1.32 \text { to } 1.9)\end{array}$ & $\begin{array}{l}1.42(0.4) \\
(1.14 \text { to } 1.69)\end{array}$ & $\begin{array}{l}1.35(0.5) \\
(1.02 \text { to } 1.67)\end{array}$ & $\begin{array}{l}1.48(0.71) \\
(0.93 \text { to } 2.02)\end{array}$ \\
\hline $\mathrm{TT}_{0.1} *$ & $\begin{array}{l}0.019(0.008) \\
(0.013 \text { to } 0.025)\end{array}$ & $\begin{array}{l}0.034(0.022) \\
(0.017 \text { to } 0.051)\end{array}$ & $\begin{array}{l}0.024(0.01) \\
(0.017 \text { to } 0.031)\end{array}$ & $\begin{array}{l}0.046(0.021) \\
(0.031 \text { to } 0.06)\end{array}$ & $\begin{array}{l}0.059(0.026) \\
(0.039 \text { to } 0.079)\end{array}$ \\
\hline $\operatorname{Tlim}(s)^{* *}$ & $\begin{array}{l}422(186) \\
(288 \text { to } 555)\end{array}$ & $\begin{array}{l}429(249) \\
(237 \text { to } 620)\end{array}$ & $\begin{array}{l}256(195) \\
(125 \text { to } 387)\end{array}$ & $\begin{array}{l}202(197) \\
(70 \text { to } 334)\end{array}$ & $\begin{array}{l}121(81) \\
(59 \text { to } 183)\end{array}$ \\
\hline
\end{tabular}

Data are presented as mean (SD) with $95 \%$ confidence interval.

BMI, body mass index; VC, vital capacity; MVV, maximal voluntary ventilation; VT, tidal volume; RR, respiratory rate; VE, minute ventilation; Ti, inspiratory time; Ttot, total breath time; Ti/Ttot, duty cycle; MIP, maximum inspiratory pressure; $\mathrm{P}_{0,1}$, occlusion pressure; $\mathrm{TT}_{0.1}$, tension-time index; Tlim, muscle endurance time.

Group 1, no assisted ventilation (NIPPV) and 24/24 h normocapnia; group 2, nocturnal hypercapnia prior to start of NIPPV implementation; group 3, nocturnal NIPPV with no breathlessness; group 4, nocturnal NIPPV with breathlessness; group 5, full-time NIPPV.

${ }^{*} \mathrm{p}<0.05 ;{ }^{* *} \mathrm{p}<0.01 ;{ }^{* * *} \mathrm{p}<0.001$ (ANOVA). 
recorded by a heated Fleisch No 2 pneumotachometer (Metabo, Lausanne, Switzerland).

The spontaneous breathing pattern was compared with the maximum capacity of the respiratory system, as estimated by the best of three VC manoeuvres, three recordings of maximal inspiratory pressure (MIP) in $1 \mathrm{~s}$ performed at residual volume ${ }^{17}$ and maximal voluntary ventilation (MVV) over $15 \mathrm{~s}$. The tension-time index $\left(\mathrm{TT}_{0.1}\right)$ was calculated as $\left(\mathrm{P}_{0.1} / \mathrm{MIP}\right) \times(\mathrm{Ti} /$ Ttot). ${ }^{18}$ This is a non-invasive variation of the invasive tensiontime index of the diaphragm (TTdi) ${ }^{19}$ which is used to evaluate fatigue. For $\mathrm{TT}_{0.1}$, a value of $>0.047$ has been shown as the threshold above which the inspiratory muscles are at risk of fatigue. ${ }^{18}{ }^{20}$ For respiratory endurance, the maximal time (Tlim) the patients could hold spontaneous ventilation against a predefined load (35\% of MIP) was recorded following the method of Matecki et al. ${ }^{2}$ The spring-loaded threshold valve used by the latter was replaced by a vacuum generator (MEC, Brussels, Belgium) such as that described by Chen et $a^{21}$ and used by Hart et al.22

\section{Data analysis}

One-way analysis of variance (ANOVA) and post-ANOVA Student-Newman-Keuls were used for group comparisons. A paired $t$ test was used for paired comparisons. Data were presented as mean values with standard deviations (standard errors of the mean on figures) and the $95 \%$ confidence interval. Significance was accepted at $\mathrm{p}<0.05$.

\section{RESULTS}

Table 1 shows the morning data for each group. There was a progressive increase in age and decline in MIP, MVV and VC from group 1 to 5 . VT fell but VE was maintained by an increase in $\mathrm{RR}$, the ratio of $\mathrm{Ti}$ to Ttot remaining stable. Endurance capacity (Tlim) decreased and $\mathrm{TT}_{0.1}$ increased with age and disease progression, suggesting that more severely affected subjects were approaching respiratory muscle fatigue.

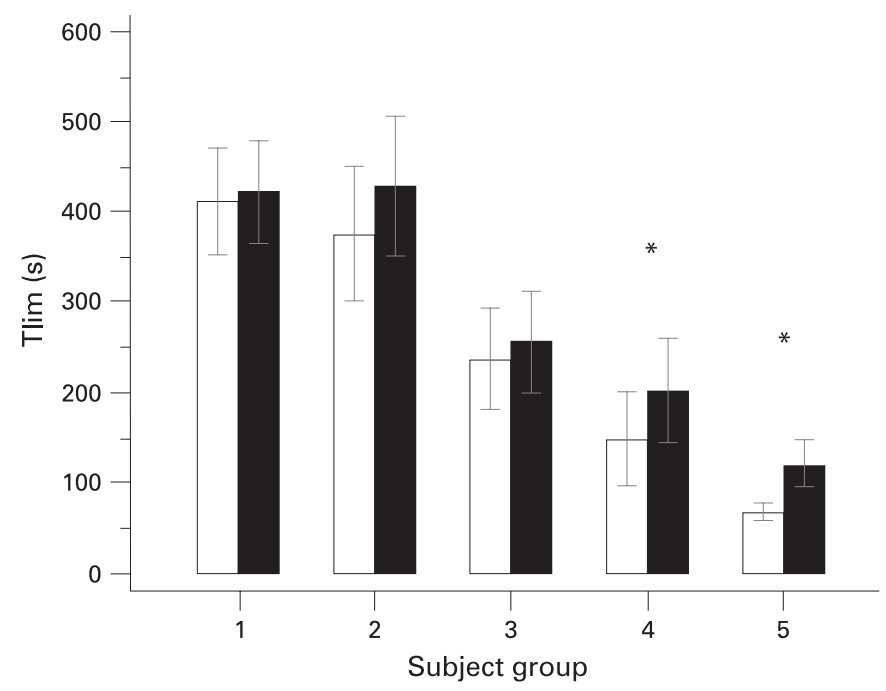

Figure 2 Endurance capacity (Tlim) in the five groups of patients with Duchenne muscular dystrophy. Columns represent mean values; errors bars represent 1 standard error of the mean (SEM). White columns: evening Tlim; black columns: morning Tlim; ${ }^{*} p<0.05$ (paired $t$ test, evening vs morning). Group 1, no assisted ventilation (NIPPV) and 24/ 24 h normocapnia; group 2, nocturnal hypercapnia prior to start of NIPPV implementation; group 3, nocturnal NIPPV with no breathlessness; group 4, nocturnal NIPPV with breathlessness; group 5, full-time NIPPV.
Figure 1 shows the effect of n-NIPPV on $\mathrm{TT}_{0.1}$. More severe respiratory muscle weakness is associated with higher $\mathrm{TT}_{0.1}$, but there is a fall between groups 2 and 3 after n-NIPPV is started. In groups 4 and $5, \mathrm{TT}_{0.1}$ is considerably lower in the morning when the subjects had just stopped n-NIPPV. Figure 2 shows the same pattern for respiratory muscle endurance. After $2 \mathrm{~h}$ of d-NIPPV, group 4 (dyspnoeic) subjects had a higher VC and Ti but lower $\mathrm{TT}_{0.1}$ (table 2).

Figure 3 compares days with n-NIPPV to days with n-NIPPV + d-NIPPV in patients in group 4. By the evening there had been a deterioration in Borg score, VC, RR, $\mathrm{TT}_{0.1}$ and Tlim, but they were still better at $20.00 \mathrm{~h}$ following d-NIPPV than the $20.00 \mathrm{~h}$ recordings on the control day when they did not have d-NIPPV. $\mathrm{TT}_{0.1}$ improved immediately after d-NIPPV, while changes in Tlim and RR were not significant at $16.00 \mathrm{~h}$ but were significant at 20.00 h. MIP and Ti/Ttot remained stable after n-NIPPV and dNIPPV. Figure 4 shows the close relationship between changes in breathlessness and $\mathrm{TT}_{0.1}$ during and after NIPPV.

\section{DISCUSSION}

We have shown that, as patients with $\mathrm{DMD}$ become more severely affected by their disease, they lose endurance capacity and adopt a breathing pattern which puts them at risk of excessive muscle loading. This is seen in patients who have already had to start n-NIPPV (group 3). In patients with nNIPPV in whom breathlessness increases during the day (groups 4 and 5), the fall in endurance capacity is more pronounced towards the end of the period of the day when they are breathing spontaneously. In these dyspnoeic patients, d-NIPPV for $2 \mathrm{~h}$ restored morning values of respiratory parameters and alleviated symptoms of dyspnoea for the remainder of the day.

Muscle fatigue involves loss of capacity for developing force and/or velocity of contraction which is reversible by rest. ${ }^{23}$ Previous studies have focused on measures of strength, such as MIP, and failed to show any significant effect of NIPPV. In our study MIP did not change, so it could be argued that we have not demonstrated respiratory muscle fatigue. We suggest that $\mathrm{TT}_{0.1}$ and Tlim appear to be more sensitive to changes in the function of the respiratory muscles and are more physiological than measures of strength. Our study could also be criticised for not documenting that NIPPV rested the respiratory muscles, but this is a consistent finding of previous studies which fits with our clinical observation of the subjects. ${ }^{24-26}$

Reduction in the work of breathing (ie, the load on the muscles) as a consequence of inflation of the chest by mechanical ventilation could also explain our results. We did not measure lung or chest wall compliance, but the small increase in VC with no change in MIP seen after n-NIPPV and dNIPPV would be consistent with increased compliance of the respiratory system, except in group 3 patients where VC was paradoxically reduced after n-NIPPV. In patients with kyphoscoliosis it has been reported that periods of daytime intermittent positive pressure breathing (IPPB) from $5-10 \min ^{27}{ }^{28}$ to $120 \mathrm{~min}^{15}$ improved VC, but in another study $20 \mathrm{~min}$ had no effect. ${ }^{29}$ No change in VC following short periods of IPPB has been observed in patients with respiratory muscle weakness. ${ }^{29} 30$ An exception is patients with amyotrophic lateral sclerosis in whom 5 min of IPPB via a mouthpiece improved static lung compliance. ${ }^{31}$ However, patients with amyotrophic lateral sclerosis may not be comparable to those with a less severe disease progression such as DMD. ${ }^{31}$

In the natural progression of $\mathrm{DMD}$, nocturnal hypercapnia precedes daytime symptoms, ${ }^{32}$ suggesting a strategy which allows $\mathrm{PaCO}_{2}$ to rise rather than subjecting the respiratory 
Table 2 Comparison of respiratory parameters at $08.00 \mathrm{~h}$ (after NIPPV) and $20.00 \mathrm{~h}$ (before NIPPV) in group 4 patients with evening breathlessness

\begin{tabular}{|c|c|c|}
\hline & $08.00 \mathrm{~h}$ & $20.00 \mathrm{~h}$ \\
\hline $\mathrm{VC}(\mathrm{ml})^{*}$ & $\begin{array}{l}704(195) \\
(573 \text { to } 835)\end{array}$ & $\begin{array}{l}642(153) \\
(539 \text { to } 745)\end{array}$ \\
\hline RR (breaths $/ \mathrm{min}$ )** & $\begin{array}{l}19.6(2.5) \\
(17.9 \text { to } 21.2)\end{array}$ & $\begin{array}{l}25.8(8.1) \\
(20.4 \text { to } 31.2)\end{array}$ \\
\hline $\mathrm{Ti} / \mathrm{T}$ tot & $\begin{array}{l}0.44(0.04) \\
(0.41 \text { to } 0.47)\end{array}$ & $\begin{array}{l}0.44(0.05) \\
(0.4 \text { to } 0.47)\end{array}$ \\
\hline MIP $\left(\mathrm{cm} \mathrm{H}_{2} \mathrm{O}\right)$ & $\begin{array}{l}14(5.6) \\
(10.2 \text { to } 17.7)\end{array}$ & $\begin{array}{l}13.6(6.1) \\
(9.5 \text { to } 17.7)\end{array}$ \\
\hline $\mathrm{TT}_{0.1}{ }^{* *}$ & $\begin{array}{l}0.046(0.021) \\
(0.031 \text { to } 0.06)\end{array}$ & $\begin{array}{l}0.081(0.035) \\
(0.58 \text { to } 0.1)\end{array}$ \\
\hline $\operatorname{Tlim}(s)^{*}$ & $\begin{array}{l}202(197) \\
\text { (70 to } 334)\end{array}$ & $\begin{array}{l}149(183) \\
\text { (26 to } 172)\end{array}$ \\
\hline $\mathrm{TccO}_{2}(\mathrm{~mm} \mathrm{Hg})$ & $\begin{array}{l}45.5(7.8) \\
(40.3 \text { to } 50.8)\end{array}$ & $\begin{array}{l}46.3(7.9) \\
(40.9 \text { to } 51.6)\end{array}$ \\
\hline
\end{tabular}

Data are presented as mean (SD) with $95 \%$ confidence intervals.

$\mathrm{VC}$, vital capacity; RR, respiratory rate; Ti, inspiratory time; Ttot, total breath time; Ti/ Ttot, duty cycle; MIP, maximum inspiratory pressure; $\Pi_{0.1}$, tension-time index; Tlim, muscle endurance time; $\mathrm{TCCO}_{2}$, transcutaneous carbon dioxide tension. ${ }^{*} \mathrm{p}<0.05 ;{ }^{* *} \mathrm{p}<0.01$ (paired $t$ test 08.00 vs $20.00 \mathrm{~h}$ ).

muscles to a load which they are unable to sustain. The sensation of breathlessness results from increasing effort as weaker muscles strive to maintain normocapnia. ${ }^{9}$ At this stage, patients adopt a breathing pattern which puts them at high risk of respiratory muscle fatigue, and their endurance is reduced as evidenced by their capacity to tolerate an external load. NIPPV reverses these changes. Recovery of respiratory drive has been demonstrated in patients with neuromuscular diseases as a longer term effect of $n$-NIPPV. We suggest that this could reflect an increase in the capacity of the respiratory muscles, allowing the respiratory centres to increase ventilation without putting the respiratory muscles at risk of fatigue.

This study also showed that $2 \mathrm{~h}$ of d-NIPPV provided similar physiological effects on spontaneous breathing and dyspnoea to a full night with NIPPV. There were some differences between dNIPPV and n-NIPPV since a nasal mask is commonly used in the lying position but is less easy to use during the daytime in the sitting position. Patients therefore chose a mouthpiece for daytime use. The main difference between mouthpiece and nasal NIPPV is that a nasal mask is used by a sleeping patient at night while a mouthpiece is used by a conscious patient during the day. During daytime ventilation, patients actively purse the lips around the mouthpiece to be fully inflated only two or three times per minute. ${ }^{9}$ Compared with the nasal mask at night, the better control on leaking and synchronism provided by the mouthpiece might explain why a short period of daytime ventilation is so effective in improving the markers for respiratory fatigue. However, the disparity between changes in $\mathrm{TT}_{0.1}$ and Tlim immediately after d-NIPPV was unexpected in the patients in group 4 with dyspnoea (fig 3 ). This disparity refers to the high intra-individual variability in this group, probably reflecting the difficulty found in some patients to undergo an endurance test immediately after relaxing their respiratory muscles with $d$ NIPPV. Four hours after d-NIPPV the disparity between $\mathrm{TT}_{0.1}$ and Tlim was significantly reduced. The correlation between changes in $\mathrm{TT}_{0.1}$ and Borg score suggest that the Borg score is a reliable marker of the load on respiratory muscles in patients in whom daytime ventilation is expected in the future. The current results suggest that additional d-NIPPV is beneficial in reducing the load on the respiratory muscles as soon as dyspnoea is present in the evening, but further research is required to confirm these benefits.

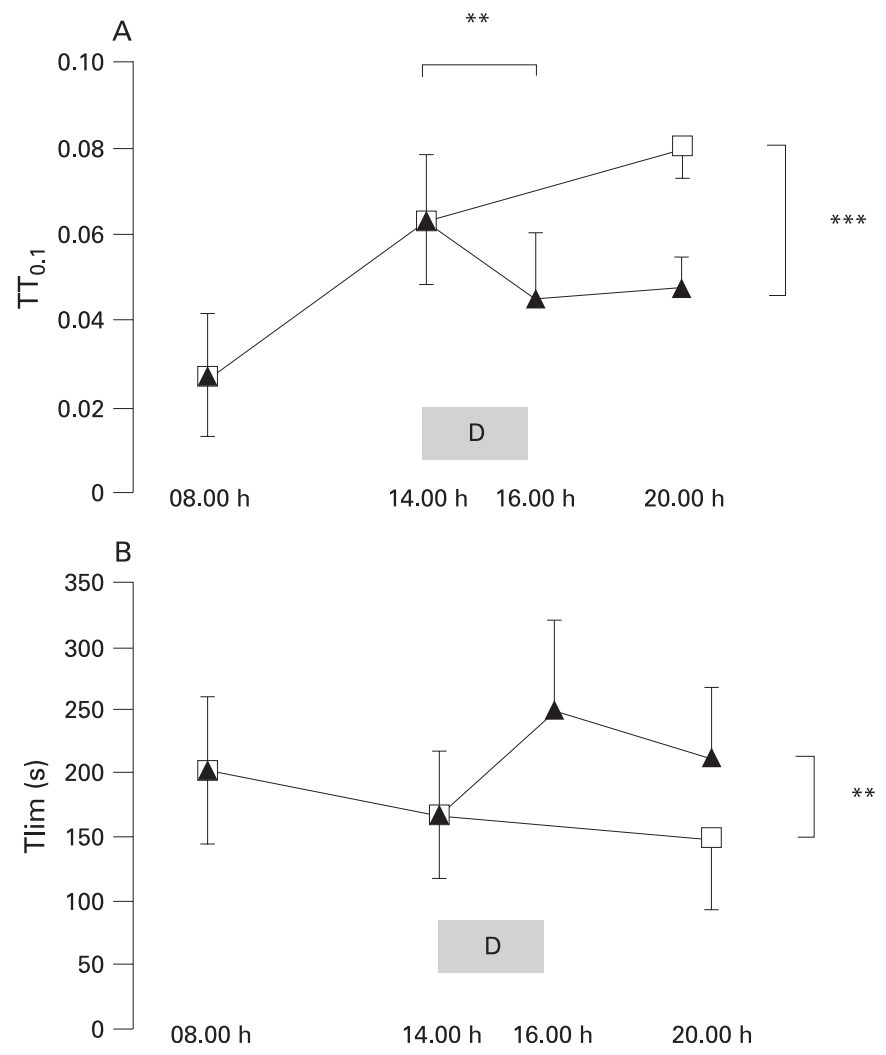

Figure 3 Effect of nocturnal $(\square)$ and diurnal $(\mathbf{\Delta})$ ventilation on daytime non-invasive tension-time index $\left(\mathrm{TT}_{0.1}\right.$, panel $\left.\mathrm{A}\right)$ and endurance capacity (Tlim, panel B) in group 4 patients with dyspnoea. The grey area represents the period of diurnal (D) mechanical ventilation. Dots represent mean values, errors bars represent SEM. ${ }^{* *} p<0.01$; ${ }^{* * *} \mathrm{p}<0.001$ (paired $t$ test).

In conclusion, our results suggest that, in patients with $\mathrm{DMD}$, the load on the respiratory muscles and associated risk of respiratory fatigue increases with respiratory muscle weakness. Several years after implementation of nocturnal NIPPV, breathlessness and other physiological markers of respiratory muscle loading rise from morning to evening. This study shows that

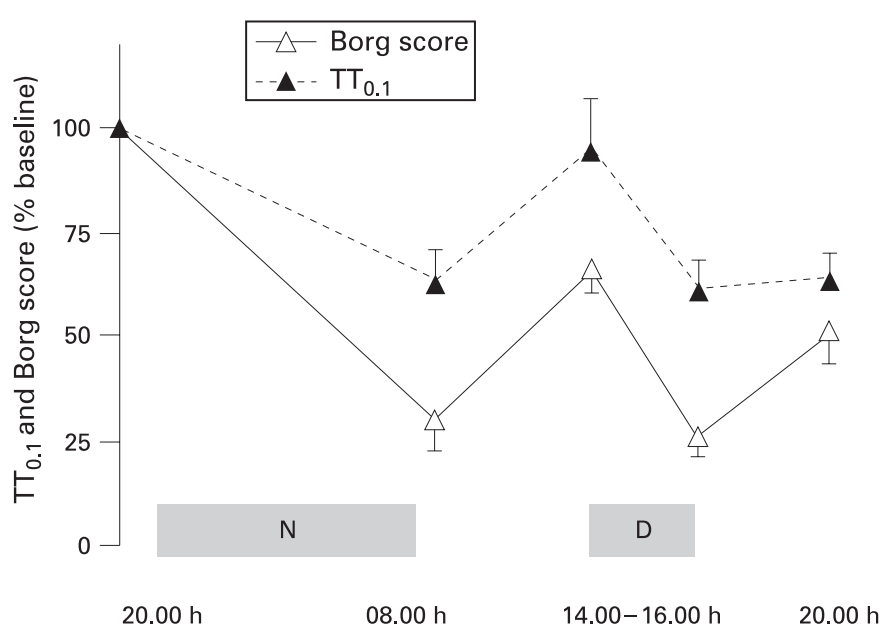

Figure 4 Changes over $24 \mathrm{~h}$ in tension-time index $\left(\mathrm{TT}_{0.1}\right)$ and breathlessness (modified Borg score on 10 points) in group 4 patients with dyspnoea. Data are presented as percentages of baseline values measured at $20.00 \mathrm{~h}$, before nocturnal NIPPV. See legend to fig 3 . 
these markers of loading and possible peripheral fatigue are closely related to dyspnoea. Both are reduced and endurance capacity enhanced following nocturnal NIPPV. Our data suggest that, in patients who are dyspnoeic when they are breathing unassisted from morning towards evening, $2 \mathrm{~h}$ of $\mathrm{d}$ NIPPV is able to reverse breathlessness and associated signs of respiratory muscle loading more effectively than n-NIPPV alone.

Funding: MT was sponsored by a Grant (No 08-2003) from ABMM (Association Belge contre les Maladies Musculaires) - Aide à la Recherche asbl.

Competing interests: None.

Ethics approval: The ethics committee of our institution approved the study. Informed consent from patients and families was obtained prior to the commencement of the study.

\section{REFERENCES}

1. Rideau Y, Jankowski LW, Grellet J. Respiratory function in the muscular dystrophies. Muscle Nerve 1981;4:155-64.

2. Matecki S, Topin N, Hayot M, et al. A standardized method for the evaluation of respiratory muscle endurance in patients with Duchenne muscular dystrophy. Neuromuscul Disord 2001;11:171-7.

3. Phillips MF, Quinlivan RC, Edwards RH, et al. Changes in spirometry over time as a prognostic marker in patients with Duchenne muscular dystrophy. Am J Respir Crit Care Med 2001;164:2191-4.

4. Begin R, Bureau MA, Lupien $L$, et al. Control of breathing in Duchenne's muscular dystrophy. Am J Med 1980;69:227-34.

5. Lanini B, Misuri G, Gigliotti F, et al. Perception of dyspnea in patients with neuromuscular disease. Chest 2001;120:402-8.

6. Hukins CA, Hillman DR. Daytime predictors of sleep hypoventilation in Duchenne muscular dystrophy. Am J Respir Crit Care Med 2000;161:166-70.

7. Toussaint $\mathbf{M}$, Steens $M$, Soudon $P$. Lung function accurately predicts hypercapnia in patients with Duchenne muscular dystrophy. Chest 2007;131:368-75.

8. Ward S, Chatwin M, Heather $\mathrm{S}$, et al. Randomised controlled trial of non-invasive ventilation (NIV) for nocturnal hypoventilation in neuromuscular and chest wall disease patients with daytime normocapnia. Thorax 2005:60:1019-24.

9. Toussaint M, Steens M, Wasteels G, et al. Diurnal ventilation via mouthpiece: survival in end-stage Duchenne patients. Eur Respir J 2006;28:549-55.

10. Toussaint M, Chatwin M, Soudon P. Mechanical ventilation in Duchenne patients with chronic respiratory insufficiency: clinical implications of 20 years published experience. Chron Respir Dis 2007:4:167-77.

11. Annane D, Quera-salva MA, Lofaso F, et al. Mechanisms underlying effects of nocturnal ventilation on daytime blood gases in neuromuscular diseases. Eur Respir J 1999:13:157-62.
12. Nickol AH, Hart N, Hopkinson NS, et al. Mechanisms of improvement of respiratory failure in patients with restrictive thoracic disease treated with non-invasive ventilation. Thorax 2005;60:754-60

13. Young HK, Lowe A, Fitzgerald DA, et al. Outcome of noninvasive ventilation in children with neuromuscular disease. Neurology 2007;68:198-201.

14. Parreira VF, Jounieaux V, Delguste $P$, et al. Determinants of effective ventilation during nasal intermittent positive pressure ventilation. Eur Respir J 1997:10:1975-82.

15. Ergun P, Aydin G, Turay UY, et al. Short-term effect of nasal intermittent positivepressure ventilation in patients with restrictive thoracic disease. Respiration 2002;69:303-8.

16. Whitelaw WA, Derenne JP, Milic-Emili J. Occlusion pressure as a measure of respiratory center output in conscious man. Respir Physiol 1975;23:181-99.

17. Black LF, Hyatt RE. Maximal respiratory pressures: normal values and relationship to age and sex. Am Rev Respir Dis 1969;99:696-702.

18. Hayot M, Ramonatxo M, Matecki S, et al. Noninvasive assessment of inspiratory muscle function during exercise. Am J Respir Crit Care Med 2000;162:2201-7.

19. Bellemare $\mathbf{F}$, Grassino A. Effect of pressure and timing of contraction on human diaphragm fatigue. J Appl Physiol 1982;53:1190-5.

20. Hussain SN, Pardy RL. Inspiratory muscle function with restrictive chest wall loading during exercise in normal humans. J Appl Physiol 1985;58:2027-32.

21. Chen RC, Que CL, Yan S. Introduction to a new inspiratory threshold loading device. Eur Respir J 1998;12:208-11.

22. Hart N, Kearny MT, Pride NB, et al. Inspiratory muscle load and capacity in chronic heart failure. Thorax 2004;59:477-82.

23. Anon. NHLBI Workshop summary. Respiratory muscle fatigue. Report of the respiratory muscle fatigue workshop group. Am Rev Respir Dis 1990:142:474-80.

24. Carrey Z, Gottfried SB, Levy RD. Ventilatory muscle support in respiratory failure with nasal positive pressure ventilation. Chest 1990;97:150-8.

25. Girault C, Richard JC, Chevron V, et al. Comparative physiologic effects of noninvasive assist-control and pressure support ventilation in acute hypercapnic respiratory failure. Chest 1997;111:1639-48.

26. Fanfulla $\mathbf{F}$, Delmastro M, Berardinelli A, et al. Effects of different ventilator settings on sleep and inspiratory effort in patients with neuromuscular disease. Am J Respir Crit Care Med 2005;172:619-24.

27. Cooper DM, Rojas JV, Mellins RB, et al. Respiratory mechanics in adolescents with idiopathic scoliosis. Am Rev Respir Dis 1984;130:16-22.

28. Simonds AK, Parker RA, Branthwaite MA. The effect of intermittent positivepressure hyperinflation in restrictive chest wall disease. Respiration 1989;55:136-43.

29. McCool FD, Mayewski RF, Shayne DS, et al. Intermittent positive pressure breathing in patients with respiratory muscle weakness. Alterations in total respiratory system compliance. Chest 1986;90:546-52.

30. De Troyer A, Deisser P. The effects of intermittent positive pressure breathing on patients with respiratory muscle weakness. Am Rev Respir Dis 1981:124:132-7.

31. Lechtzin N, Shade D, Clawson L, et al. Supramaximal inflation improves lung compliance in subjects with amyotrophic lateral sclerosis. Chest 2006;129:1322-9.

32. Anon. Clinical indications for noninvasive positive pressure ventilation in chronic respiratory failure due to restrictive lung disease, COPD, and nocturnal hypoventilation. A consensus conference report. Chest 1999:116:521-34. 